\section{Note on breeding and parental care behaviours of albino Hoary-bellied Squirrel Callosciurus pygerythrus (Rodentia: Sciuridae) in Sibsagar District of Assam, India}

\section{Girindra Kalita}

Sr. Lecturer and Head, Department of Zoology, Guwahati College, Guwahati, Assam 781021, India

Email: girin_05@yahoo.co.in

Twelve genera belonging to the Family Sciuridae are known from the Indian subcontinent (Srinivasulu et al. 2004). Some of the species occurring in the north-eastern states of India including Assam are Belomys pearsonii, Petaurista petaurista, $P$. philippensis, P. caniceps, Hylopetes alboniger, Ratufa bicolor, Dremomys lokriah, D. pernyi, D. rufigenis, Callosciurus pygerythrus, C. erythraeus and Tamiops macclellandii (Choudhury 1997).

During a field survey conducted by the team of Society for Zoology and Nature, Guwahati, between October,1997 to June, 1998, a few individuals of albino squirrel (Image 1) belonging to the species Callosciurus pygerythrus were recorded from Sibsagar district of Assam, India (Kalita 1998). Albinism in this species is rare and has not been widely reported in India (Bhattacharyya \& Murmu 2004; Sharma 2004, Mahabal et al. 2005).

The present paper deals with some of the habitats, ecology and feeding habits of the albino Callosciurus pygerythrus. One female albino individual of Callosciurus pygerythrus collected from its natural habitat along with a normal male of the same species were observed in captive conditions for five years (from 2000 to 2005) and their breeding biology and subsequent parental care behaviour recorded

Date of online publication 26 June 2009

ISSN $0974-7907$ (online) | 0974-7893 (print)

Editor: C. Srinivasulu

Manuscript details:

Ms \# 01770

Received 03 May 2007

Final received 08 May 2009

Finally accepted 30 May 2009

Citation: Kalita, G. (2009). Note on breeding and parental care behaviours of albino Hoary-bellied Squirrel Callosciurus pygerythrus (Rodentia: Sciuridae) in Sibsagar District of Assam, India. Journal of Threatened Taxa 1(6): 358-360.

Copyright: () Girindra Kalita 2009. Creative Commons Attribution 3.0 Unported License. JoTT allows unrestricted use of this article in any medium for non-profit purposes, reproduction and distribution by providing adequate credit to the authors and the source of publication.

Acknowledgements: Author is thankful to the Oil and Natural Gas Corporation Ltd. India, Assam State Department of Forest and Social forestry division, Sibsagar district of Assam, Society for Zoology and Nature, Guwahati College and Principal, Guwahati College for their help in various ways and cooperation during the study. Author is also thankful to Dr. M.M. Goswami, Professor, Department of Zoology, Gauhati University due to his encouragement in revising the scientific paper.

\section{OPEN ACGESS | FREE DOWNLOAD}

\section{Methods}

The approach to locate the albino squirrels of the species Callosciurus pygerythrus was through questionnaire surveys to ascertain the presence of albino squirrels, and thorough surveys of the entire Sibsagar District. Communities in direct contact with the forest as tribals and the Muga keepers were interviewed for vital information on the sightings of this species.

One individual albino squirrel out of two encountered was captured with the help of the villagers of that area for observation on its breeding and parental care behaviour. The squirrel was housed in a $6 \times 4.5 \times 3.6 \mathrm{~m}$ cage of iron net constructed in a private place, in a well ventilated condition, and a normal male individual of the same species was introduced into the cage. The roof of the cage was covered with thatch. Shade was also arranged to protect the cage from high temperatures. The inside of the cage was decorated with potted shrubs and dry pieces of bamboo with holes at internodes. The cage was also provided with a small tray for drinking water. The water was renewed and the cage was cleaned every day. Fresh fruits and nuts like bananas, oranges, pineapples, coconuts, betel nut and seeds or fruits of Ficus spp., Azadirachta indica, Nerium indicum (ripe fruit) and Bombax ceiba, were provided as normal diet. Fruits, nuts and seeds were selected from observations in its natural habitat. Some times orthopteran insects like grasshoppers and crickets were also included in the diet. Curd was the favoured food of the albino variety and was a convenient medium for administering oral drugs and vitamins.

No special treatment was provided for their breeding in captivity, except giving a drop of vitamin $\mathrm{E}$ from a freshly punctured IP $200 \mathrm{mg}$ liquid vitamin E capsule along with $20 \mathrm{ml}$ curd every morning during September 2002 to October 2004.

\section{Observations}

Morphologically, the albino squirrel is completely white, the tail faded white, eyes red and ears untufted; fore limbs with 4 toes and hind limbs with 5 toes. Total length is $30 \mathrm{~cm}$, body $12 \mathrm{~cm}$ and tail $18 \mathrm{~cm}$.

Information regarding the existence of albino squirrels in the study areas is quite localized. The squirrels were observed to prefer a rich and varied habitat consisting predominantly of Bamboo, Ficus spp., Azadirachta indica, Bombax ceiba, and various other fruit plants and wild shrubs and trees. This is owing to the proximity to the two major rivers, the Disang and the Dikho cutting through the Sibsagar District. Observed habitat of albino squirrel is plain villages near two main rivers of Sibsagar district namely, Disang and Dikho. The population of this albino variety in its habitat is observed to be very low. Maximum 3 individuals were recorded in 1995 in a village of that area. A detailed list of its occurrence in the studied areas has been incorporated in Table 1.

Albino squirrels in their natural habitat are quite lethargic. They never go up to the tip of their supporting trees. In most cases they are observed up to a maximum height of 20 feet. During the day they mostly remain sitting on the low branches of bushy trees. However, they become active at dawn and at dusk.

In their natural habitat they were observed consuming 
Table 1. Occurrence of albino Hoary-bellied Squirrel in villages of Sibsagar District surveyed during 1997-98 (Data based on local villagers' information).

\begin{tabular}{|c|c|c|c|c|}
\hline S.No. & $\begin{array}{l}\text { Year of } \\
\text { occurrence }\end{array}$ & $\begin{array}{l}\text { Total number of } \\
\text { individual recorded }\end{array}$ & Area of its occurrence & Status \\
\hline 1 & $1992-93$ & 1 & Lankok village & Information source is not reliable. Status not known \\
\hline 2 & 1995 & 3 & Kujibali village & 1 captured by the villagers and another one killed. \\
\hline 3 & 1996 & 2 & Kujibali and Barpatragohaingaon village & 1 was killed by some villagers. The rest 1 was captured by a villager. \\
\hline 4 & 1997 & 2 & Gohaingaon village & 1 killed \\
\hline 5 & 1998 & 2 & Kujibali and Barpatragohaingaon village & Observed in wildln the month of June \\
\hline 6 & 1999 & 2 & Kujibali and Barpatragohaingaon village & 1 captured \\
\hline 7 & 2001 & - & - & Could not be traced \\
\hline 8 & 2003 & 1 & Betbari & Observed during June-July \\
\hline 9 & 2005 & - & - & Could not be traced \\
\hline
\end{tabular}

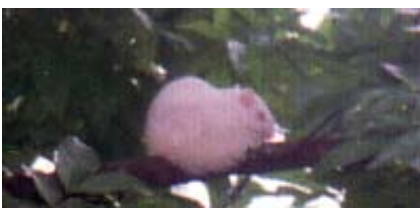

Image 1. An albino Hoarybellied Squirrel in wild wild

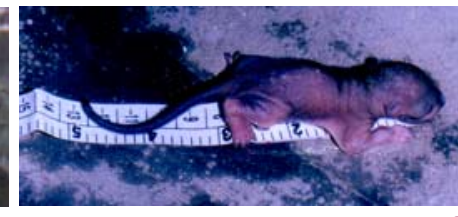

Image 2. A new born baby of albino squirrel
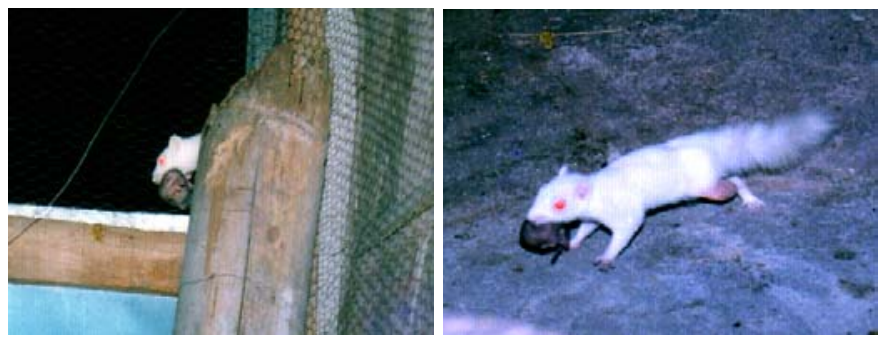

Images 3\&4. Albino squirrel showing parental care by carrying her baby in mouth

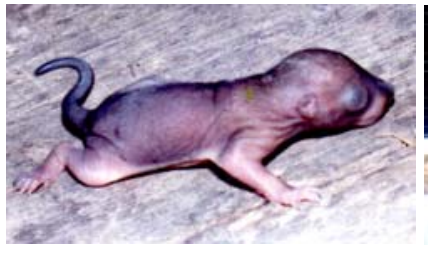

Image 5. Close up view of a 15-day old male baby born to the albino squirrel

fruits, nuts, bark born fungus and insects infesting Ficus spp., Olea europaea, Bombax ceiba, Bambusa spp. and Dendrocalamus spp.

Breeding and parental care habit of albino squirrel in captivity

The male Callosciurus pygerythrus in captivity exhibited hostile behaviour towards the albino female. In the first two years of captivity (2000 \& 2001) breeding was not observed. However, after adding vitamin $\mathrm{E}$ to the diet in the third year (2002) the pair exhibited courtship behaviour from the last week of September (2002) and were observed occupying the same hole during that period. From first fortnight of October, the female was observed collecting dry leaves and thatch as nest building material. In the last week of April 2003, the female gave birth to a single male pup. The new born baby was black in colour and about $13 \mathrm{~cm}$ in length (Image 2). Its eyes remained closed for 22 days (Image 5). The individual was born in a hairless condition. However, normal hairs developed and grew thicker and longer to resemble the normal male individual except for a morphological dissimilarity of a slightly tufted ear (Image 6). During that period the mother squirrel was observed to be aggressive towards the male driving him away from the hole/drey. She suckled the pup at intervals of 40 to 70 minutes. She exhibited parental care behaviour by transferring the pup as and when there was a disturbance by carrying it in her mouth to a safer place in the cage. Even after every handling of the pup for photography she transferred it to a new drey (Images $3 \& 4$ ). The first baby survived in captivity till August, 2003.

Breeding was observed in the second consecutive year too, and a male offspring was born on the 4th of May 2004 and attained its full grown stage. During the study, the albino squirrel did not exhibit pairing tendency with her male baby. The adult male was not aggressive towards the male baby and play between them was often observed. However, he was aggressive towards the baby during the time of feeding.

The mother albino squirrel survived till 18th February, 2005. During her survival no courtship behaviour with her baby was observed.

\section{Discussion}

Albinism in wild animals is not very common. However, there are previous reports on albinism in some species of mammals including squirrel in India and abroad (Gee 1959; Walker 1968; Tehsin \& Chawra 1994; Kalita 1998; Bhattacharyya \& Murmu 2004; Sharma 2004; Mahabal et al. 2005). The occurrence of the present albino variety of Callosciurus pygerythrus in the studied areas in Sibsagar district of Assam was discovered as early as 1995. The emergence of this albino species to such a new territory might be due to its migration from other territories of forest cover, which is yet to be ascertained. It is known that variations in coat colour may develop among squirrels living in the same place (Prater 1980). However, it is very difficult to ascertain the species status of albinos unless one goes through a genetic study. The present albino variety is found together with the colony of gray $C$. pygerythrus. Individuals of albinos differ from the gray $C$. pygerythrus in only the following points.

- The coat colour of the albino variety is snow white; but, the gray squirrel bears gray hair on its dorsal surface and smoke white to the ventral.

- Eyes of the albino variety are red, but it is black in gray species.

- Tail fur in albino variety is thicker and longer than the gray species. 
- Gray squirrels are not friendly to the albino variety.

- Albinos are lethargic in comparison to the gray species.

All these differences may be due to their body physiology and has the scope for further study. Although there appears no significant difference between the albino and the gray variety of the studied species apart from the above, the breeding performance in captivity brings forth to an idea for considering. it under the same species category of C.pygerythrus.

Accurate observation on the life history of most of the rodents in the wild is very difficult as they are evasive and fleet in nature (Lang 1925). Vitamin E is a long investigated drug in reproductive physiology in different animals particularly in rodents (Hafez 1970) which has been tried here. Earlier it was investigated in laboratory reproduction of squirrel like, Citellus tridecemlineatus pallidus Allen by George \& Wade (1931). However, in rodents, the requirement of vitamin $\mathrm{E}$ in reproduction is species related (Hafez 1970). Though administration of vitamin $\mathrm{E}$ as oral dose in ground squirrel like, C. tridecemlineatus pallidus Allen does not affect in reproduction (George \& Wade 1931), present observation signifies its requirement as oral dose in the reproduction of Callosciurus pygerythrus.

The parental care behaviour of carrying its offspring by the squirrel and other rodents is unlike that of cat species (Lang 1925). However, they also use the mouth to carry their young during danger (Lang 1925). Lang (1925) has confirmed the babies cooperation in maintaining balance during its shifting from one place to an other by the mother, as studied in a Central American squirrel, Sciurus hoffmanni which the present study contradicts that in early stages the babies are too weak to provide support by holding their mother with the help of tail or legs (Images $3 \& 4$ ). The baby supports its mother only by bending its head and tail parts in an inward direction (Images $3 \& 4)$.

It is known that normally the litter size in most of the species is 2-4 pups and they breed 2-3 times in a year (Walker 1968; Prater 1980). However, the development of single fetus during April-May in the present observations is significant and may be a reason for its lower population in the study area. The lethargic nature of the albino variety in day time may be related to their biological inability to cope with strong daylight.
The present study may be regarded as base-line information for breeding experiments in albino squirrel in the region. Further study is required for more information regarding breeding and parental care behaviour of the animal. However, albinos are at a distinct disadvantage in nature as they are easy prey and subject to killing out of curiosity. The urgent need of conservation measures on this rare animal is emphasized.

\section{References}

Bhattacharyya, T.P. \& A. Murmu (2004). First record of occurrence of Albino Hoary-bellied Himalayan squirrel Callosciurus pygerythrus lokroides (Hodgson) [Rodentia: Sciuridae]. Records of Zoological Survey of India 103(Part 3-4): $181+$ pl-1.

Choudhury, A. (1997). Checklist of the Mammals of Assam. Gibbon books with Assam Science Technology \& Environment Council, 103pp.

Kalita, G. (1998). A Preliminary Survey Report on the occurrence of white squirrels in Sibsagar District of Assam. Society for Zoology and Nature, Guwahati College, Guwahati, 6pp.

Gee, E.P. (1959). Albinism and partial albinism in Tigers. Journal of the Bombay Natural History Society 56(3): 581-587.

George, E.J. \& N.J. Wade (1931). Laboratory reproduction studies on the ground squirrel, Citellus tridecemlineatus pallidus, Allen. Biological Bulletin 16(PT1): 101-114

Hafez, E.S.E. (1970). (Ed) Reproduction and Breeding Techniques for Laboratory Animals. Lea \& Febiger. Philadelphia, 375pp.

Lang, H. (1925). How squirrels and other rodents carry their young. Journal of Mammalogy 6(PT1): 18-24.

Mahabal, A., R.M. Sharma \& M.S. Pradhan (2005). A case of total albinism in the Five-stripped Palm Squirrel Funambulus pennanti Wroughton in Sindhudurg district, Maharastra state. Journal of the Bombay Natural History Society 102(1): 98.

Prater, S.H. (1980). The Book of Indian Animals. Bombay Natural History Society, Mumbai. 324pp.

Sharma, S.K. (2004). Occurrence of albino common palm civet and northern palm squirrel in Southern Rajasthan. Zoos' Print Journal $19(5): 1483$.

Srinivasulu, C., S. Chakraborty \& M.S. Pradhan (2004). Checklist of Sciurids (Mammalia: Rodentia: Sciuridae) of South Asia. Zoos' Print Journal 19(2): 1351-1360.

Tehsin, R. \& C.S. Singh (1994). Albino Common Mongoose (Herpestes edwardsi Geoffroy) sighted near Udaipur. Journal of the Bombay Natural History Society 91(2): 304-305.

Walker, E.P. (1968). Mammals of the World (Vol-II) 2nd Edition. Published by- The Johns Hopkins Press, Baltimore, 1500pp.

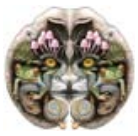

